\section{CLINICAL REMARKS \\ on}

\section{CERTAIN CHANGES OBSERVED IN THE URINE \\ IN MYXGEEMA AFTER THE ADMINISTRA- TION OF GLYCERINE EXTRACT OF THYROID GLAND.}

By WILLIAM M. ORD, M.D., F.R.C.P.,

Physician and Lecturer on Medicine at St. Thomas's Hospital; AND

EDMUND WHITE, B.Sc.LoND.

A patient suffering from myxœdema was admitted to st. Thomas's Hospital on April 19th, 1893. After careful daily examination of the food and the urine, she began, on May 1st, to take 20 drops of a glycerine extract of the thyroid body of the sheep daily. The dose was equivalent to a sixth part of the whole thyroid body of the sheep. We beg to submit a short statement of the observations obtained.

For a week previous to May 1st the patient had been placed on a diet carefully ordered so that its elements should be as much as possible the same day by day. The particulars of this diet and its equivalents in chemical examination will be published subsequently. The same diet was maintained after the administration of the thyroid extract during the whole period of the treatment of the patient in hospital.

After the administration of the thyroid extract a marked change was observed both in the volume of urine passed and in the quantity of nitrogen excreted. An increase in the volume of urine is the first point to be noted. As regards the excretion of nitrogen, the quantity up to the time of the administration of the thyroid extract corresponded fairly with the amount of nitrogen taken in the food, being, as one would expect, slightly less. Bearing in mind this fact that before treatment the nitrogen excreted in the urine was slightly less than that taken in the food, it is of importance to note that three days after the first administration of the thyroid extract the excretion of nitrogen in the urine exceeded the amount introduced in the food, and that this proportion, very much marked in the earlier days of treatment, was practically maintained so long as the patient was under observation.

The total nitrogenous excretion was determined, as well as the excretion of urea, in order to ascertain whether the nitrogen might be excreted in any form other than urea. The records show that the relation of total nitrogen to nitrogen as urea remained about the same as in normal urine, thus indicating that the nitrogen was still excreted chiefly as urea. It was also seen that the difference between organic matter and urea remained about the same during the continuance of the experiment, thus showing that, in addition to water, the increased excretion was urea or other nitrogenous matter. At the same time, it is important to notice that the patient lost weight rather rapidly in the first week of treatment-namely, from 8 st. $4 \frac{1}{2} \mathrm{lbs}$. to 7 st. $13 \mathrm{lbs}$., with a further but more gradual loss of $3 \mathrm{lbs}$. The temperature of the body was raised; before treatment it had been subnormal, ranging from $96.6^{\circ}$ to $98.6^{\circ} \mathrm{F}$., ranging afterwards from $97.6^{\circ}$ to $100^{\circ}$, the maximum temperature being reached on the thirteenth day after treatment had begun. As regards the loss of weight, we have to take into account the fact that the patient, having previously a very dry skin, had free perspiration after the administration of the drug.

With regard to the excretion of inorganic matter, it had occurred to us that, with the increased excretion of urea and the associated rise of temperature, changes in the excretion of saline matters, such as occur in pyrexia, might be looked for. It appears, however, that in this case the excretion of the inorganic substances determined was very little affected by the thyroid treatment.

The acidity of the urine was observed to follow closely the variation in the quantity of phosphoric acid eliminated, thus being evidently due to acid sodium phosphate as in normal urine. It is to be regretted that the sulphates in the urine have not been determined, seeing that they might have shown whether the increased nitrogenous excretion might be referred to destruction of proteid substances or some other form of nitrogenous matter.

We beg to present the following conclusions as the result of the treatment and observations in this case :

1. That the urine is increased in volume.

2. That the nitrogen excreted in the urine exceeds the total quantity of nitrogen in the food.

3. The phosphoric acid and chlorine elimination are practically unaffected.

4. That the increased nitrogenous excretion is chiefly in the form of urea.

5. That the body weight is rapidly diminished.

6. That the temperature of the body is raised.

We append a chart showing the changes in the weight of the body, the nitrogenous value of the food taken daily, and the excretion of nitrogen after treatment.

We propose, also, to publish later a full report of our observations, with the tables illustrating them.

MAY

JUNE

$\begin{array}{llllllllllllllllllllllllllllllllllllllllllll}25 & 26 & 27 & 28 & 29 & 30 & 1 & 2 & 3 & 4 & 5 & 6 & 7 & 8 & 9 & 10 & 11 & 12 & 13 & 14 & 15 & 16 & 17 & 18 & 19 & 20 & 21 & 22 & 23 & 24 & 25 & 26 & 27 & 28 & 29 & 30 & 31 & 1 & 2\end{array}$

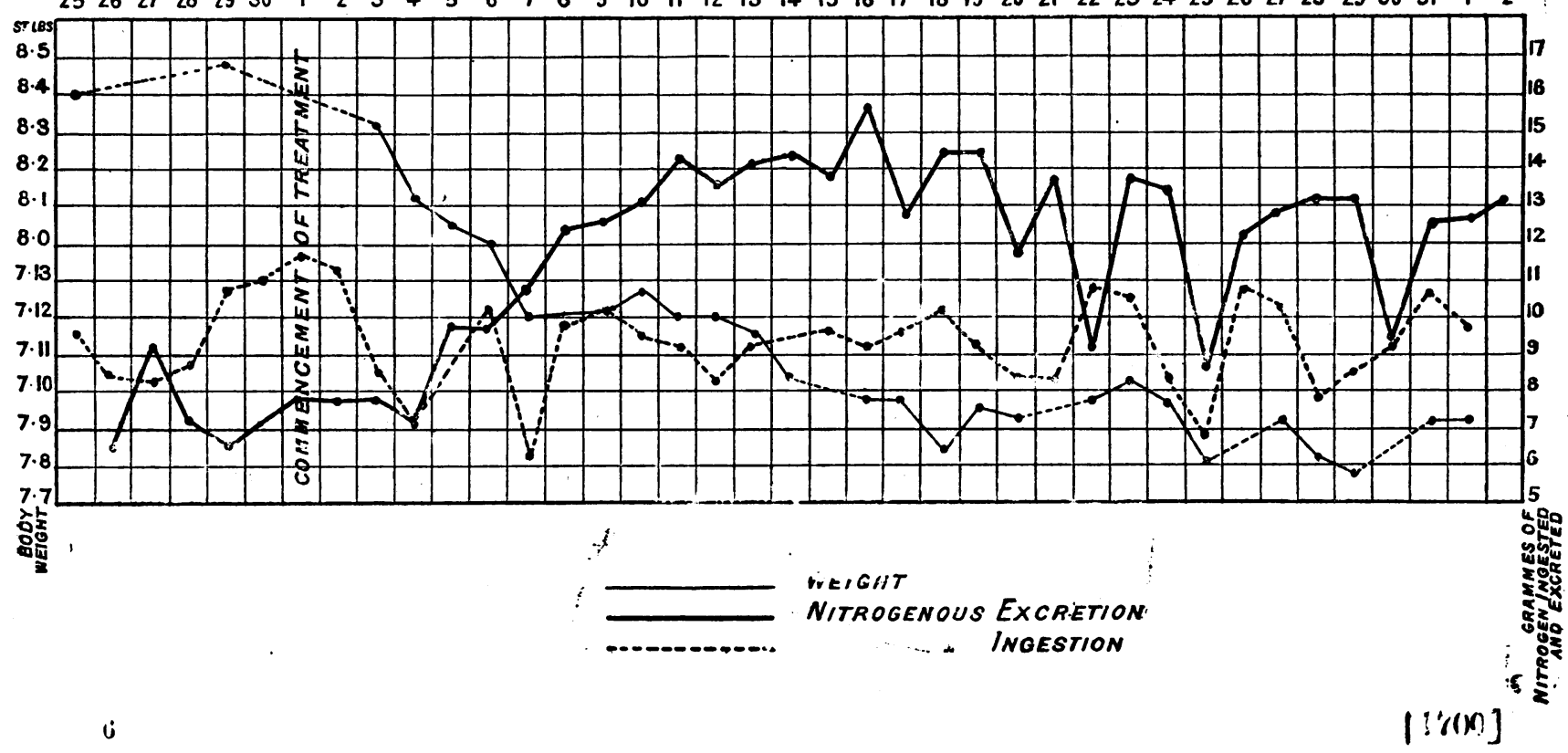

